\title{
ANALYZING THE PHYSICAL TRAINING PREPARATION IN FIREFIGHTER'S RELAY RACE WITH OBSTACLES 4 x 100 m
}

\author{
Ioan Sabin SOPA \\ "Lucian Blaga" University, Sibiu, Romania \\ sopa_sabin@yahoo.com \\ Marcel POMOHACI \\ "Lucian Blaga" University, Sibiu, Romania \\ marcelpomohaci@yahoo.com
}

\begin{abstract}
Firefighters have a demanding and difficult mission both physical and mental so their training must be rigorous and well prepared, therefore they should have good physical resistance, strength, speed, and coordination. Our study focuses on the $4 \times 100 \mathrm{~m}$ race with obstacles and how should firefighters physically prepare for the race. We had two different samples that form the first and second team of ISU Sibiu in the competition of firefighters of $4 \times 100 \mathrm{~m}$ race with obstacles, formed by 10 males with age of $30 \pm 3.5$ years old with experience in this kind of competitions between 2 and 7 years. We presented our training program and the effects on the results of our athletes and also analyze the efficiency of developing motor qualities such as strength, speed, resistance and coordination. The results show relatively good improvements in the performance time in any of the fourth exchanges and also in the motor qualities level. Conclusions of our research present the efficiency of training athletic skills and also the motor qualities in obtaining better results at the $4 \times 100 \mathrm{~m}$ race with obstacles.
\end{abstract}

KEYWORDS: psychomotor testing, physical training, firefighter's competitions, 4 x 100 firefighter relay race

\section{Introduction}

Some specialists affirm that firefighting is a physically and mental demanding occupation that includes strenuous duties performed over long shifts (10-12 h), often across consecutive days (Aisbett et al. 2012; Vincent et al., 2015; Chappel et al., 2016). Involving a multitude of risks for injury. The factors contributing to these risks of injury or physical damage include hazards on a unsafe ground, fatigue, and carrying of asymmetric loads (i.e. carrying tools with one arm or hose over one shoulder) (Kong et al., 2013; Angelini et al. 2018).
The apparition of fatigue is a common occurrence during firefighting tasks (Barr et al., 2010). Also the exposure to high temperatures and the associated heat stress have been proven to have exponential physiological and psychological effects on firefighters (Smith et al., 2001; Horn et al., 2011), not least of which is a rapid onset of muscular fatigue (Nielsen et al., 2001). Fatigue has also been found to increase gait variability (Kong et al., 2010), reduce balance (Hur et al., 2014), impair sense of limb position (Allen \& Proske, 2006), and increase the frequency of obstacle crossing 
contact errors in firefighters (Park et al., 2011).

Physically taxing activities performed by firefighters may include hauling hose, using heavy extrication equipment, or lifting and transporting patients (Ministry of Internal Affairs of Romania, 2015; Haddock et al., 2011; Donovan et al., 2009). Given the importance of fitness for firefighters, innovative techniques for improving their overall fitness responsive to the unique training needs, culture, and environment of the fire service are needed (Jahnke et al., 2015).

\section{Objectives of the Research}

The objectives of our research was to present the $4 \times 100 \mathrm{~m}$ relay race at the firefighter's contests and to analyze the methods of physical preparation in order to improve the physical resistance through athletic exercises.

\section{Research Method}

Contests for professional emergency services in Romania are organized annually, by stages, in the emergency inspectorates of Bucharest, under the coordination of the General Inspectorate for Emergency Situations. The competition events are the same as those of international fire competitions organized by the International Committee for Fire Prevention and Extinction (CTIF).

The contest events and the number of competitors at each team are:

- ladder competition - 8 competitors,

- obstacle 100 meters run 8 competitors,

- the relay race $4 \times 100$ meters 2 teams with 4 competitors,

- realizing the intervention device 7 competitors.

The " $4 \times 100$ meters relay race" competition (Ministry of Internal Affairs of Romania, 2007).

The teams participate with two pears, each consisting of 4 competitors (representing shifts), each team is entitled to one attempt. The sportive 1,2 and 3 are equipped with training shoes, sports shoes, waistband, and helmet, and the 4th sportive with a fireproof protective suit, waistband, helmet with visor and fire resistant gloves (KEVLAR type). The test takes place on an Olympic track and filed (for athletics) with a length of 400 meters, marked distinctly with two, three or four lines. The materials are placed at the starting line according to the regulations in Figure no. 1.

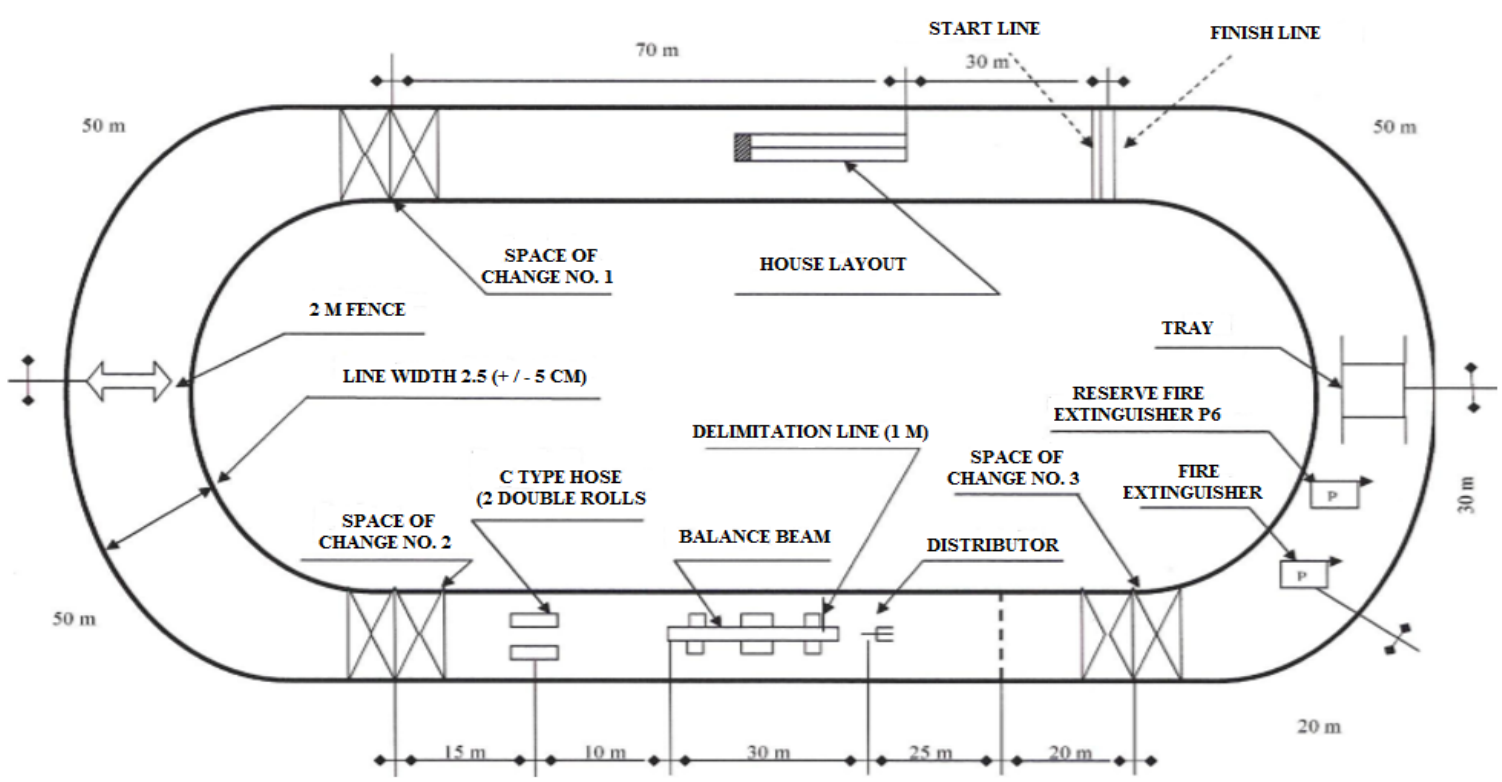

Figure no. 1: The relay race $4 \times 100$ meters 
At the start the competitors take up their seats at the starting line at the assigned placement, performing the following procedures.

- The first exchange comes at the starting line with a cane ladder and a " $C$ " pipe (for the relay race). At the "START!" signal, the competitor runs with the ladder in their hands and climb over the model box, continues to run for another 60 meters, enters the first exchange space and hands the relay into the hand of the next teammate. When the sportive climbs the model box with the help of the ladder, 0.5 liters of petrol is introduced into the tray.

- The second exchange, after receiving the pipe, runs and climbs the twometer fence. At the moment of touching the soil, the mixture in the tray (containing 40 liters of water, 5 liters of diesel and 0.5 liters of petrol) is lit. After escalation, the sportive continues his running for another 40 meters and enters the exchange area, where he gives the relay stick.

- The third exchange, after receiving the pipe, the sportive attaches it to the girdle, runs and raises the two C-type rollers, crosses the balance beam, spreads the rollers and connects them together, the free connections are remaining in the sportive hands, the sportive connects it to the distributor and the other free connection to the "C" pipe, which, after passing the marked line of 280 meters from the starting line, discards it and, reaching the exchange space, and gives to the next sportive the relay stick.

- The forth exchange, the sportive is running with the pipe to the grid forward to the tray, raising the extinguisher with dust and $\mathrm{CO} 2$, extinguishing the fire (including the one outside the tray, if it occurs), continues running another 50 meters and crosses the finish line. The test is considered finished when the fire was extinguished, and the 4th shift passed the finish line.

\subsection{Research Hypothesis}

If the training and improvement programs regarding the motor-specific motor qualities proposed in this paper were promoted and developed in a scientific, attractive, innovative and professional way by coaches/trainers, then we can affirm that this programs will ensure the progress in the development of the athletes in the lot, would ensure an exponential increase in the performances of each individual athlete, as well as the improvement of the results of professional competitions for emergencies from year to year.

3.2. Research Place and Sample. Period and Location of the Research

The research took place between March-September 2018 at the Inspectorate for Emergency Situations from Sibiu and was formed by 4 phases that consisted in competitions on detachments of every emergency firefighter post, competitions on counties of Sibiu Inspectorate - local competition, competitions on region (Inspectorates from Braşov, Covasna, Harghita, Mureș and Sibiu), final stage at Iaşi (best 12 teams of emergency firefighters in Romania).

\subsection{Subjects of the Research}

The research subjects were selected among the Inspectorate for Emergency Situations from Sibiu team and were composed of 10 males with age between 27-33 years old (with an average of 30.2 \pm 3.5 years old) and an experience in the specific contest between 2-7 years old. The intervention plan (the training and development of motor qualities and specific skills needed for the $4 \times 100$ meters with obstacle race). The experimental stage was continued after the observation and interpretation of the kinematic parameters with the monitoring and evaluation of the results that allowed us to know, identify the technical faults and develop the motor skills of the athletes in order to adapt some 
corrective measures. For the purpose of correction, a suitable motor program for monitoring and evaluation of the technical preparation of the specific tests at the professional emergency services competitions.

In cooperation with Inspectorate for Emergency Situations Sibiu, we agreed that this motor-based program based on athletic exercises and motor quality development exercises should be done as closely as possible with the proposed model, which corresponds to what the athlete has chosen as the reference subject has repeated several times before to acquire a precise motor image and a sequence of movements corresponding to the correct execution.

\section{Designing the Training Process} Execution on Segments and on the Entire of the Test "4 x 100 m Relay"

Training in the execution of the race.

- $30 \mathrm{~m}$ run with the ladder, handling the ladder, climbing and run over the house, descent and run $70 \mathrm{~m}$ ( 2 exercises).

- $50 \mathrm{~m}$ run, $2 \mathrm{~m}$ fence escalation, and $50 \mathrm{~m}$ run ( 2 exercises).

- $15 \mathrm{~m}$ run, lift the "C" rollers, run $10 \mathrm{~m}$, climb over the balance beam, bind the rollers and connect them, run $30 \mathrm{~m}$, connect it to the distributor, $45 \mathrm{~m}$ run and pipe connection ( 2 exercises).
- $30 \mathrm{~m}$ run, take the extinguisher, run $20 \mathrm{~m}$, leave the extinguisher and run $50 \mathrm{~m}$ ( 2 exercises).

- Exercises for learning / consolidating / improving the relay exchange technique:

- ex. for transmitting the position on the spot at the transmitter signal;

- ex. for the transmission of the relay stick from walking;

- ex. for transmitting the relay stick from a moderate tempo and then at increasing speed (passing the stick inside the exchange space).

- $15 \mathrm{~m}$ run with the pipe at the girdle, lifting two C-type hoses, passing over the beam, connecting the hoses to one another, to the distributor and the pipe ( 2 exercises).

- $20 \mathrm{~m}$ run with the pipe at the waist, picking up and manual shaking of the extinguisher, extinguishing the fire from the tray and passing the finish line (2 exercises).

- Training in the execution of the segment with the ladder (shift 1) Barem: less than 15 seconds.

- Training in the race barem Barem: Less than 70 seconds.

\section{Results}

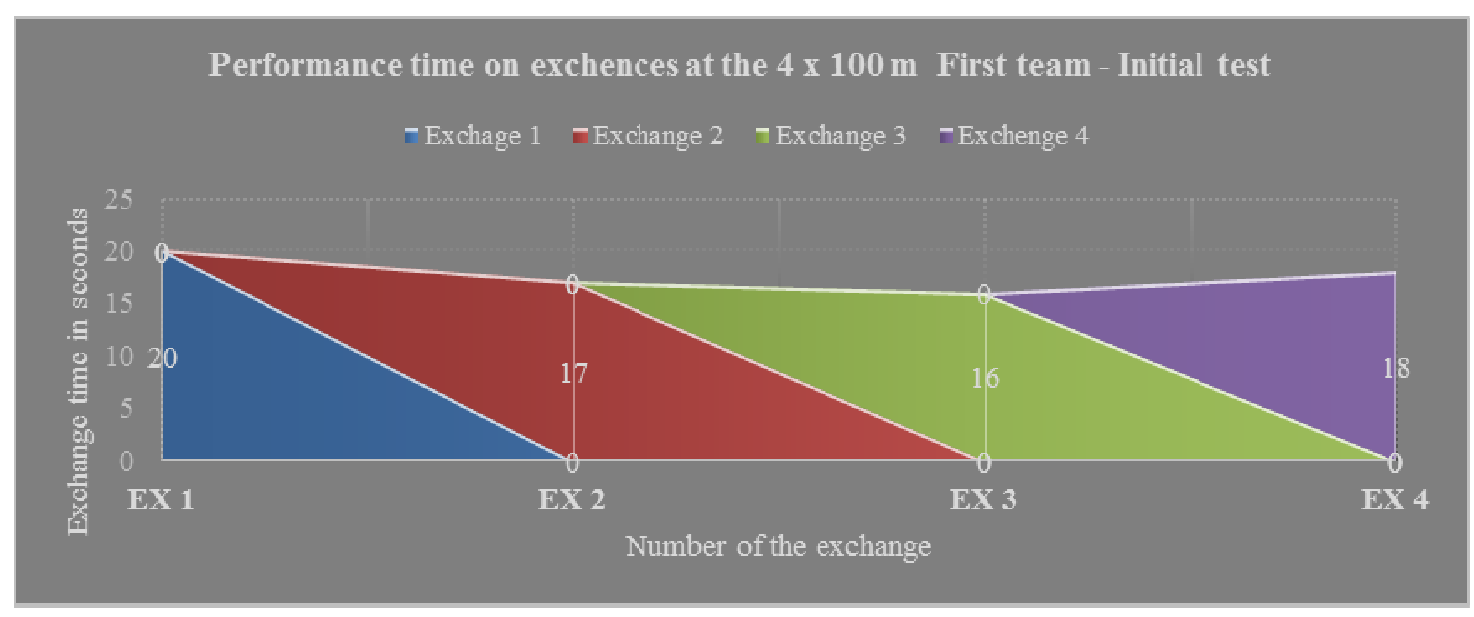

Figure no. 2: Performance time on exchanges at the $4 \times 100 \mathrm{~m}$ obstacle race First Team - Initial test 


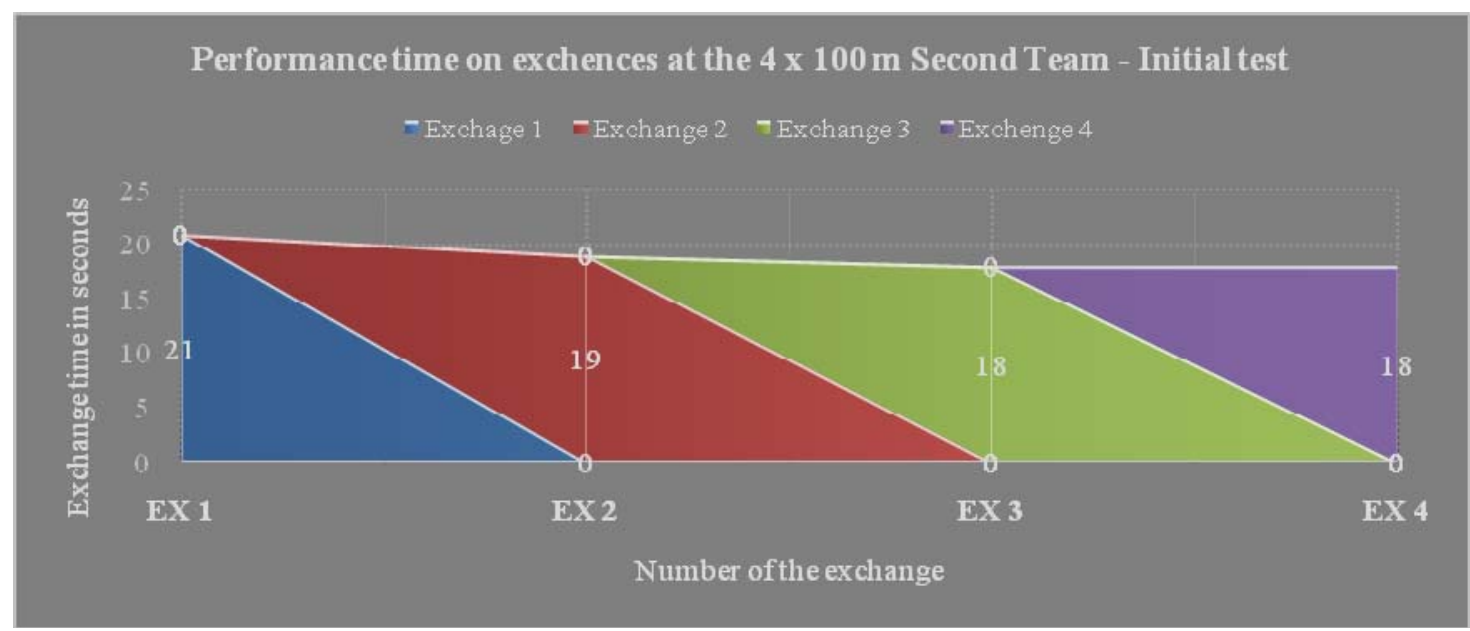

Figure no. 3: Performance time on exchanges at the $4 x 100$ obstacle race Second Team - Initial test

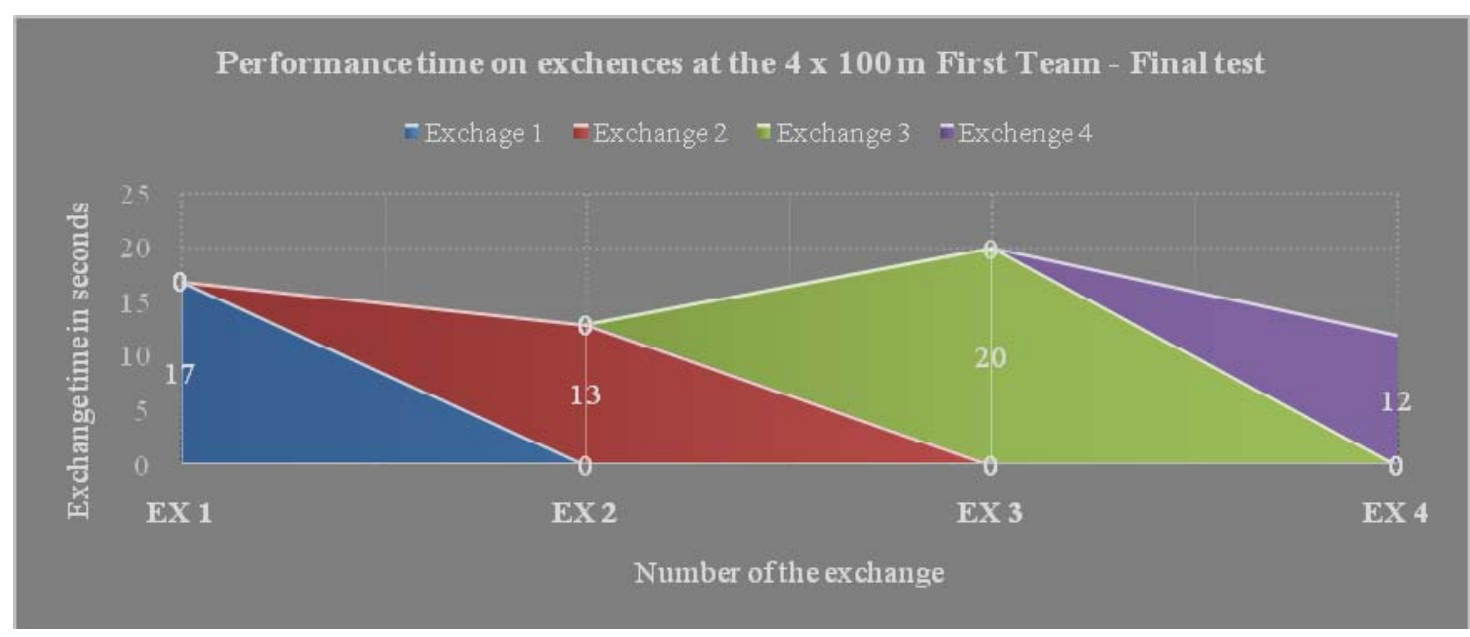

Figure no. 4: Performance time on exchanges at the $4 \times 100 \mathrm{~m}$ obstacle race First Team - Final Test

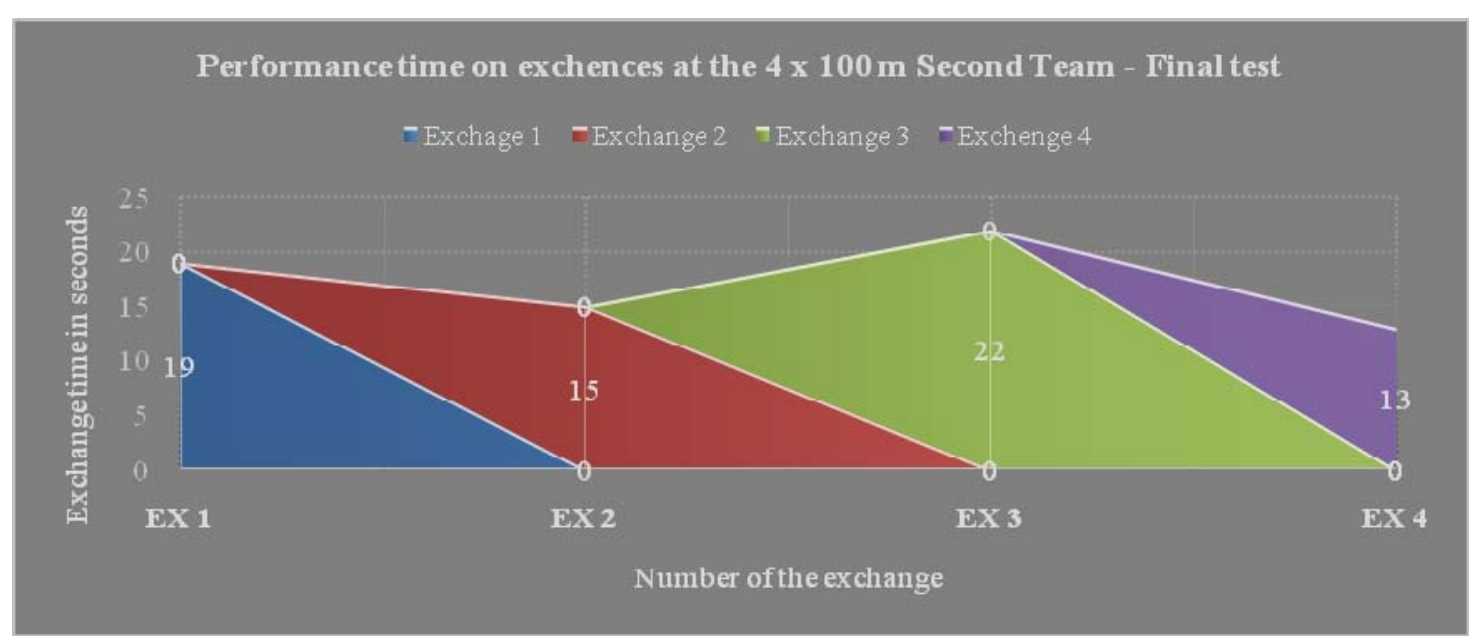

Figure no. 5: Performance time on exchanges at the $4 \times 100 \mathrm{~m}$ obstacle race Second Team-Final Test 


\section{Discussions}

Firefighters are not only set to fight fire but also respond to emergency situations to search, rescue, and protect health and community property (Braedley, 2015). Understanding physical fitness contribution with respect to firefighting task completion times would provide firefighters with new insights into more efficient and proper training strategies (Nazari et al., 2018).

The results of our research highlighted the following information:

- the registered parameters at the final testing at the first team of firefighters compared with the initial testing at the $4 \times 100 \mathrm{~m}$ race with obstacle were improved at the first exchange with 3 seconds (from 20 to 17 seconds), at the second exchange with 4 seconds (from 17 to 13 seconds), at the third exchange the result was weaker than the first testing with 4 seconds (16 to 20 seconds), and at the forth exchange we registered the best improvement of 6 seconds at the final test compared with the initial test.

- at the second team of firefighters we registered at the initial testing of the $4 \times 100 \mathrm{~m}$ race with obstacle at the first exchange an improvement of 2 seconds (from 21 to 19 seconds), at the second exchange we had an improvement of 4 seconds (from 19 to 15 seconds), at the third exchange we registered a weaker time at the final test compared with the initial test with 4 seconds (from 18 to 22 seconds), and at the last exchange the forth we registered an improvement of 5 seconds (from 18 to 13 seconds).

As we can see the training program using athletic exercises proven to be a good way to develop and improve speed, strength and specific technique of the $4 \times 100 \mathrm{~m}$ race with obstacles. Also improving coordination and balance prove to be an effective training method in improving time in every exchange at the $4 \times 100 \mathrm{~m}$ race with obstacles. Specific monitoring of training and analytical use of kinetic observation of the movement allowed us to analyze and improve methods of training and results at the conquests. Numerous studies have demonstrated a direct association between better firefighting job performances with higher levels of physical fitness (Michaelides et al., 2011). Two aspects of fitness, cardiorespiratory and muscle strength, have received a great deal of attention. Cardiorespiratory fitness is an essential contributing factor to improved performance and enables firefighters to carry out on-duty tasks more efficiently (Perroni et al., 2013).

\section{Conclusions}

The conclusions of our investigation highlighted that using a well-planned training and analyzing the kinetic specific movement at the $4 \times 100 \mathrm{~m}$ race with obstacles we can improve performance of the firefighters. Specific development of balance and coordination can also contribute in improving performance of firefighters in the $4 \times 100 \mathrm{~m}$ race with obstacles. Firefighter's 4 x 100 m race with obstacles is a specific test that can reproduce real critical situations. Firefighters need to keep up in good physical shape and improve and develop their skills so that they can intervene prompt in critical situations. 


\section{REFERENCES}

Aisbett, B., Wolkow, A., Sprajcer, M., \& Ferguson, S. A. (2012). Awake, smoky, and hot: Providing an evidence-base for managing the risks associated with occupational stressors encountered by wildland firefighters. Applied Ergonomics, Vol. 43, 916-925.

Allen, T. J., \& Proske, U. (2006). Effect of muscle fatigue on the sense of limb position and movement. Experimental Brain Research, Vol. 170, Issue 1, 30-38.

Angelini, M. J., Kesler, R. M., Petrucci, M. N., Rosengren, K. S., Horn, G. P., \& HsiaoWecksler, E. T. (2018). Effects of simulated firefighting and asymmetric load carriage on firefighter obstacle crossing performance. Applied Ergonomics, Vol. 70, 59-67.

Barr, D., Gregson, W., \& Reilly, T. (2010). The thermal ergonomics of firefighting reviewed. Applied Ergonomics, Vol. 41, Issue 1, 161-172.

Braedly, S. (2015). Pulling men into the care economy: The case of Canadian firefighters. Competition and Change, Vol. 19, Issue 3, 264-278.

Chappel, S. E., Aisbett, B., Vincent, G., \& Ridgers, N. D. (2016). Firefighters' physical activity across multiple shifts of planned burn work. International Journal of Environmental Research and Public Health, Vol. 13, 973.

Donovan, R., Nelson, T., Peel, J., Lipsey, T., Voyles, W., \& Israel, R. G. (2009). Cardiorespiratory fitness and the metabolic syndrome in firefighters. Occupational Medicine, Vol. 59, 487e 92.

Haddock, C., Poston, W. S. C., \& Jahnke, S. A. (2011). Addressing the epidemic of obesity in the United States Fire Service. Greenbelt, MD: National Volunteer Fire Council.

Horn, G. P., et al. (2011). Physiological recovery from firefighting activities in rehabilitation and beyond. Prehosp. Emerg. Care, Vol. 15, Issue 2, 214-225.

Hur, P., Rosengren, K. S., Horn, G. P., Smith, D. L., \& Hsiao-Wecksler, E. T. (2014). Effect of protective clothing and fatigue on functional balance of firefighters. Journal of Ergonomics, Vol. 2, Issue 2.

Jahnke, S. A., Hyder, M. L., Haddock, C. K., Jitnarin, N., Day, R. S., \& Poston Walker, S. C. (2015). High-intensity fitness training among a national sample of male career firefighters. Safety and health at work, Vol. 6, 71-74.

Kong, P. W., Beauchamp, G., Suyama, J., \& Hostler, D. (2010). Effect of fatigue and hypohydration on gait characteristics during treadmill exercise in the heat while wearing firefighter thermal protective clothing. Gait Posture, Vol. 31, Issue 2, 284-288.

Kong, P. W., Suyama, J., \& Hostler, D.(2013). A review of risk factors of accidental slips, trips, and falls among firefighters. Safety Science, Vol. 60, 203-209.

Michaelides, M. A., Parpa, K. M., Henry, L. J., Thompson, G. B., \& Brown, B. S. (2011). Assessment of physical fitness aspects and their relationship to firefighters' job abilities. The Journal of Strength and Conditioning Research, Vol. 25, Issue 4, 956-965.

Ministry of Internal Affairs of Romania. (2007). Regulamentul privind organizarea şi desfăşurarea concursurilor serviciilor profesioniste pentru situaţii de urgenţă 13/05/2007. Vaslui, Romania: Author.

Ministry of Internal Affairs of Romania. (2015). Inspectoratul General pentru Situaţii de Urgenţă. Ordinul Inspectorului General al Inspectoratului General pentru Situaţii de Urgenţă. Nr.153-IG din 19.02.2015 privind organizarea şi desfăşurarea pregătirii personalului operativ din subunităţile de intervenţie ale serviciilor de urgență profesioniste (06/2015). 214, București, Romania: Author. 
Nazari, G., MacDemid, J. C., Sinden, K. E., \& Overend, T. J. (2018). The relationship between physical fitness and simulated firefighting task performance. Rehabilitation Research and Practice Journal, 1-7.

Nielsen, B., Hyldig, T., Bidstrup, F., González-Alonso, J., \& Christoffersen, G. R. J. (2001). Brain activity and fatigue during prolonged exercise in the heat. Pflügers Archiv, Vol. 442, Issue 1, 41-48.

Park, K., Rosengren, K. S., Horn, G. P., Smith, D. L., \& Hsiao-Wecksler, E. T. (2011). Assessing gait changes in firefighters due to fatigue and protective clothing. Safety Science, Vol. 49, Issue 5, 719-726.

Perroni, F., Cortis, C., Minganti, C., Cignitti, L., \& Capranica, L. (2013). Maximal oxygen uptake of Italian firefighters: Laboratory vs. field evaluation. Sport Sciences for Health, Vol. 9, Issue 2, 31-35.

Smith, D. L., Manning, T. S., \& Petruzzello, S. J. (2001). Effect of strenuous live-fire drills on cardiovascular and psychological responses of recruit firefighters. Ergonomics, Vol. 44, Issue 3, 244-254.

Vincent, G. E., Aisbett, B., Hall, S. J., \& Ferguson, S. A. (2015). Fighting fire and fatigue: Sleep quantity and quality during multi-day wildfire suppression. Ergonomics, Vol. 59, Issue 7, 932-40. 